\title{
Effects of Mangosteen Pericarp Extracts Against Mammary Cancer
}

\author{
Masa-Aki Shibata ${ }^{1 *}$, Yoshinobu Matoba ${ }^{2}$, Hideki Tosa $^{3}$ and Munekazu linuma ${ }^{4}$ \\ ${ }^{1}$ Laboratory of Anatomy and Histopathology, Graduate School of Health Sciences, Osaka Health Science University, Japan \\ ${ }^{2}$ Komeda Pharmaceutical Co., Ltd., Japan \\ ${ }^{3}$ Field \& Device Co., Japan \\ ${ }^{4}$ Laboratory of Pharmacognosy, Gifu Pharmaceutical University, Japan
}

\begin{abstract}
The pericarp of the mangosteen fruit, Garcinia mangostana Linn, has a long history of use as a medicinal plant in Southeast Asia. The actions of mangosteen extracts have been scientifically supported and it has become a popular natural health-promoting dietary supplement. Mangosteen extracts, particularly a-mangostin, induced apoptosis via the mitochondrial pathway, cell cycle arrest by p2 $11^{\text {cip } 1}$ induction and Akt dephsophorylation in mammary cancer cells; these anti-proliferative effects are associated in vivo with suppression of tumor growth and metastasis in mouse mammary cancer models. Such preclinical evidence suggests that mangosteen extracts have potential chemotherapeutic and/or chemopreventive uses.
\end{abstract}

Keywords: a-Mangostin; Mangosteen; Xanthones; Mammary cancer; Metastasis

Abbreviations: Brdu: 5-Bromo-2'-Deoxyuridine; FFPE: FormalinFixed Paraffin-Embedded; MMTV: Mouse Mammary Tumor Virus; Mtor: Mammalian Target of Rapamycin; PCNA: Proliferating Cell Nuclear Antigen; PI3K: Phosphatidylinositol 3-Kinase; TUNEL: Terminal Deoxynucleotidyl Transferase-Mediated Dutp-FITC Nick End-Labeling; vWF: Von Willebrand Factor

\section{Introduction}

The mangosteen (Garcinia mangostana Linn) has been dubbed the "queen of fruit" in its native Thailand. Mangosteens are round fruits roughly $4-8 \mathrm{~cm}$ in size with a thick, brittle, deep purple spherical outer pericarp; the edible snow white endocarp consists of 4 to 8 -segmented wedge-shaped arils (Figure 1A). When damaged, the pericarp secretes a yellow substance (Figure 1B) that acts to protect the fruit from bacterial infection. The secretion also apparently functions as an insect repellant.

Mangosteen pericarp has a long history of medicinal use in both Chinese and Ayurvedic medicine. For centuries, people in Southeast Asia have used dried mangosteen pericarp as an antiseptic, an antiinflammatory, an anti-parasitic, an antipyretic, an analgesic, and as a treatment for skin rashes [1]. The yellow exudate from the mangosteen pericarp contains a class of compounds called xanthones, including $\alpha$-mangostin, $\beta$-mangostin, $\gamma$-mangostin, garcinone $B$, and garcinone $E$, along with mangostinone, tanins, and a flavonoid called epicatechin [1]. The chemical structures of $\alpha$-mangostin, $\beta$-mangostin, $\gamma$-mangostin are shown in Figure 1C. Mangosteen products have become popular natural dietary health supplements and the effects of mangosteen extracts have had recent scientific support. Within the arena of anticarcinogenic natural products, the characteristic anti-proliferative effects of a-mangostin, an extract of the mangosteen pericarp, has received a great deal of attention. It is shown to induce cell cycle arrest and apoptosis in various types of human cancer cells [2-5], as well as to inhibit cell invasion and migration in mammary and prostate cancer cells. $\alpha$-Mangostin is further associated with down-regulation of MMP2 and MMP-9 [6,7].

Several animal cancer models demonstrate the anti-tumor effects of mangosteen extracts. Formation of aberrant crypt foci, a putative preneoplastic lesion in rat colon carcinogenesis, is significantly suppressed by dietary administration of a crude mangosteen derivative comprised of $78 \%$ a-mangostin and 16\% $\gamma$-mangostin [8]. Mangosteen extracts induce a similar anti-tumor effect in HCT 116 human colorectal carcinoma cells in nude mice [9]. a-mangostin also significantly suppresses tumor growth associated with cell cycle arrest in a xenograft mouse model of prostate cancer [10].

We recently found the anti-tumor effects of panaxanthone, a mangosteen extract comprised of $75-85 \%$ a-mangostin and 5-15\% $\gamma$-mangostin, and of purified $\alpha$-mangostin in a mouse metastatic mammary cancer model carrying a p53 mutation, a model which demonstrates a metastatic spectrum similar to that seen in human breast cancers $[11,12]$. We further analyzed the mechanisms of anti-tumor effects induced by a-mangostin in vitro, using both human and mouse metastatic mammary carcinoma cells, and in vivo in an established mouse mammary cancer model $[12,13]$. Here, we summarize the results of these experiments.

\section{Dietary Administration of Panaxanthone on Mouse Xenograft Model of Mammary Cancer}

\section{Cell line}

The BJMC3879 cell line is derived from a metastatic focus within a lymph node of a BALB/c mouse originally inoculated with purified MMTV virus; the virus was obtained from media in which Jyg-MC cells, established from mammary tumors of the Chinese wild mouse, were previously grown [14]. Mammary tumors developing in syngeneic mice injected with BJMC3879 cells show a high metastatic propensity, especially to lymph nodes and lungs $[15,16]$. This cell line contains a p53 mutation [17].

*Corresponding author: Masa-Aki Shibata, Laboratory of Anatomy and Histopathology, Graduate School of Health Sciences, Osaka Health Science University, 1-9-27 Temma, Kita-ku, Osaka, 530-0043, Japan, Tel: +81-6-75069046; Fax: +81-6-6352-5995; E-mail: masaaki.shibata@ohsu.ac.jp

Received August 20, 2013; Accepted September 20, 2013; Published September 23, 2013

Citation: Shibata MA, Matoba Y, Tosa H, linuma M (2013) Effects of Mangosteen Pericarp Extracts Against Mammary Cancer. Altern Integ Med 2: 139. doi:10.4172/2327-5162.1000139

Copyright: (c) 2013 Shibata MA, et al. This is an open-access article distributed under the terms of the Creative Commons Attribution License, which permits unrestricted use, distribution, and reproduction in any medium, provided the original author and source are credited. 


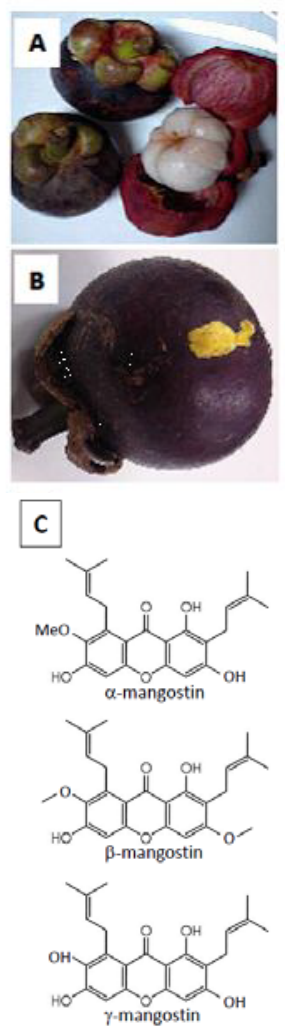

Figure 1: Gross appearance of manogsteen and chemical structures of $\alpha-, \beta$ - and $\gamma$-mangostin (A) Mangosteen is a round fruit with a thick, brittle, deep purple spherical outer pericarp. The edible snow white endocarp is composed of 4 to 8 -segmented wedge-shaped arils. (B) When damaged, the mangosteen pericarp secretes a yellow exudate for protection from infection and insects. (C) The chemical structures of mangosteen extracts: $\alpha$-mangostin molecular formula $\mathrm{C}_{24} \mathrm{H}_{26} \mathrm{O}_{6}$, molecular weight $410 ; \beta$-mangostin molecular formula $\mathrm{C}_{25} \mathrm{H}_{28} \mathrm{O}_{6}$, molecular weight $424 ; \gamma$-mangostin molecular formula $\mathrm{C}_{23} \mathrm{H}_{24} \mathrm{O}_{6}$, molecular weight 396 .

\section{Dietary administration of panaxanthone}

We injected BJMC3879 cells subcutaneously into the inguinal region of female BALB/c mice. Two weeks post-inoculation, mice were fed powder diet containing $0,0.25$, or $0.5 \%$ of panaxanthone, a crude mangosteen extract made up of $75-85 \%$ a-mangostin and $5-15 \% \gamma$-mangostin. Using calipers, we measured the size of each mammary tumor weekly and calculated tumor volumes using the formula 'maximum diameter $\times(\text { minimum diameter })^{2} \times 0.4$ ' [18]. After 8 weeks of treatment, we euthanized the animals and the mammary tumors, selected lymph nodes (i.e. lymph nodes from axillary and femoral regions as well as any that appeared abnormal) and lungs were removed and portions of each immediately fixed in $10 \%$ phosphatebuffered formalin. Fixed tissue sections were processed through to paraffin embedding, cut at $4 \mu \mathrm{m}$ and stained with hematoxylin and eosin $(\mathrm{H} \& \mathrm{E})$ for histopathological examination or mounted unstained for immunohistochemistry.

\section{Survival rates, tumor growth and metastasis}

No treatment-related prolongation of the survival rates was observed in this study. The induced mammary tumors were uniformly moderately differentiated adenocarcinomas. As assessed by computed volume, primary tumor growth was significantly suppressed in mice fed panaxanthone at $0.25 \%$ and $0.5 \%$ from weeks 3 and 2 , respectively, when compared with the control group. The numbers of metastatic lung foci $>250 \mu \mathrm{m}$ per mouse were significantly reduced in both the $0.25 \%$ and $0.5 \%$ groups as compared with the control animals, and the number of metastatic lymph nodes per mouse tended to decrease in a dose-dependent manner; however, statistical significances were not observed because of the large variations among control animals.

\section{Blood microvessel density in mammary tumors}

Unstained sections from formalin-fixed paraffin-embedded (FFPE) tumors were immunohistochemically stained with von Willebrand factor (vWF). The blood microvessel density in tumors, as inferred by the number of immunopositive blood microvessels counted, was significantly decreased in mice fed $0.5 \%$ panaxanthone when compared to that in controls.

\section{Cell proliferation and apoptosis}

Unstained tumor sections from FFPE tissues were also immunohistochemically stained with proliferating cell nuclear antigen (PCNA) and terminal deoxynucleotidyl transferase-mediated dUTPFITC nick end-labeling (TUNEL). Tumor cell proliferation, assessed by positive PCNA staining, was significantly suppressed in mice fed panaxanthone at $0.25 \%$ and $0.5 \%$ when compared with the control group, while cellular apoptosis, assessed as the number of TUNELpositive cells, was significantly elevated in mice fed $0.5 \%$ panaxanthone as compared with tumors in the control group.

\section{Osmotic-Pump Administration of Purified a-Mangostin on Mouse Xenograft Model of Mammary Cancer}

\section{Cell line}

In this study, we used the BJMC3879Luc2 mammary carcinoma cell line [19] which is generated by stable transfection of the luc2 gene (an improved firefly luciferase gene) into the parent BJMC3879 cell line described in the previous experiment. The BJMC3879Luc2 cell line is bioluminescent and allows in vivo imaging for staging and quantifying expansion of metastasis [19]. The BJMC3879Luc2 cell line also contains the p53 mutation of the parent line $[12,20,21]$.

\section{Osmotic-pump administration of purified $\alpha$-mangostin}

Since it is difficult and expensive to obtain large amounts of purified a-mangostin for dietary feeding, the compound was continuously administered via subcutaneously implanted mini-osmotic pumps (Alzet model 2002) at either 10 or $20 \mathrm{mg} / \mathrm{kg} /$ day. BJMC3879Luc2 cells were subcutaneously implanted as previously into the inguinal region of female BALB/c mice. Three weeks later, when tumors had reached approximately $0.4-0.6 \mathrm{~cm}$ in diameter, mice was implanted with miniosmotic pumps calibrated to release 0,10 or $20 \mathrm{mg} / \mathrm{kg} / \mathrm{day}$ a-mangostin for 6 weeks. One hour prior to euthanasia at study termination, mice were injected intraperitoneally with $50 \mathrm{mg} / \mathrm{kg}$ 5-bromo-2'deoxyuridine (BrdU) as a means to quantify the degree of tumor cell proliferation through DNA synthesis. Measurements of tumor volume and histopathology examination were conducted in the same manner as in the previously described feeding study.

\section{Survival rates and tumor growth}

Survival rates were significantly higher in the $20 \mathrm{mg} / \mathrm{kg} /$ day group when compared to the control group. Tumor growth was significantly inhibited in the $20 \mathrm{mg} / \mathrm{kg} /$ day group from week 1 to 5 as compared tumor growth in control mice. 
Citation: Shibata MA, Matoba Y, Tosa H, linuma M (2013) Effects of Mangosteen Pericarp Extracts Against Mammary Cancer. Altern Integ Med 2: 139. doi:10.4172/2327-5162.1000139

Page 3 of 5

\section{Bioluminescence imaging and metastasis}

Bioluminescence imaging provides an indication of metastatic growth based on the quantity and relative signal strength of tissues expressing luciferase. Animals receiving $20 \mathrm{mg} / \mathrm{kg} / \mathrm{day}$ a-mangostin tended to show decreased metastatic expansion overall; in particular, the number of lymph node metastases per mouse was significantly decreased in the $20 \mathrm{mg} / \mathrm{kg} /$ day group as compared to the control group (Figures $2 \mathrm{~A}$ and $2 \mathrm{~B}$ ). In the lungs, the number of metastatic foci per mouse $>1 \mathrm{~mm}$ tended to be lower in the $20 \mathrm{mg} / \mathrm{kg} /$ day group as compared to the control group.

\section{Lymphatic vessel invasion}

We immunohistochemically stained FFPE mammary tumor sections with podoplanin, a lymphatic endothelial marker. The number of dilated lymphatic vessels having intraluminal tumor cells (a measure of lymphatic vessel invasion) was significantly decreased in the group receiving a-mangostin at $20 \mathrm{mg} / \mathrm{kg} / \mathrm{day}$ as compared to those of control mice (Figures 2C and 2D).

\section{Microvascularization density in mammary tumors}

Using the endothelial cell marker CD31, immunohistochemical
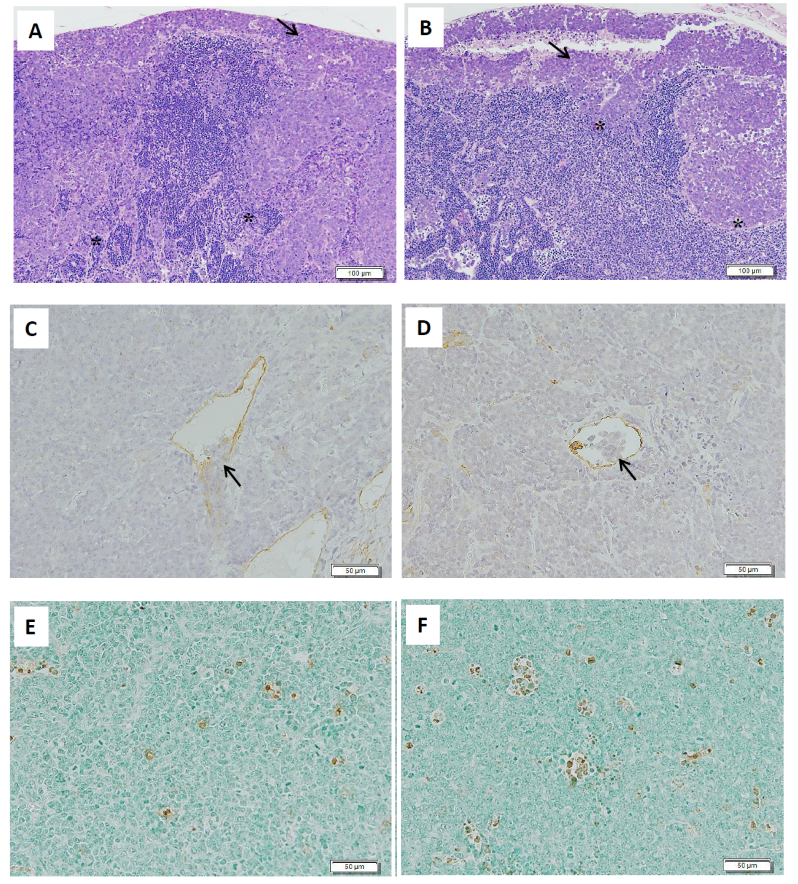

Figure 2: Histopathology and immunohistochemical staining of lymph node metastasis and mammary carcinomas of mice treated with $\alpha$-mangostin (A) Metastatic carcinoma cells fill the subcapsular sinus (arrow, surface zone) to the sinusoidal space (asterisks, deep zone), destroying lymphatic follicles in an untreated control. (B) Metastatic carcinoma cells fill the subcapsular sinus (arrow) and partially invade the sinusoidal space (asterisks) in tumors exposed to $\alpha$-mangostin. (C) Podoplanin-positive lymphatic vessels (brown) in untreated tumors were often dilated and showed invasion by tumor cells (arrow) in control mice. (D) Cancer cells were also observed in the intraluminal space of the dilated lymphatic vessels in the tumor of a mouse given $\alpha$-mangostin (arrow). (F) TUNEL-positive apoptotic cells (brown) are more frequently seen in the tumor tissue of a mouse given $\alpha$-mangostin than in the tumor tissue of a control mouse (E). A and B, H \& E stain, $\times 100 ; C$ and $\mathrm{D}$ immunohistochemistry for podoplanin (a marker for lymphatic endothelia cells), $\times 200$; E and F, TUNEL staining (detection of apoptotic cell death), $\times 200$. analysis of vascular microvessel density revealed significantly lower microvascularization in mammary tumors exposed to 10 and $20 \mathrm{mg} /$ $\mathrm{kg} /$ day $\alpha$-mangostin as compared to untreated tumors.

\section{Cell proliferation and apoptosis in mammary tumors}

BrdU labeling indices indicated a trend to lower cell proliferation rates in mammary carcinomas exposed to $20 \mathrm{mg} / \mathrm{kg}$ a-mangostin, but this decrease was not statistically significant. However, apoptosis of tumor cells, as assessed by TUNEL staining, was significantly increased in tumors from mice treated with $20 \mathrm{mg} / \mathrm{kg} /$ day $v$ s. control (Figures $2 \mathrm{E}$ and $2 \mathrm{~F}$ ).

\section{Mechanistic analyses}

Apoptosis: Activities of caspase-3, caspase-8, and caspase- 9 were significantly increased in BJMC3879Luc2 cells treated with $12 \mu \mathrm{M}$ a-mangostin. Furthermore, cytosolic cytochrome $c$ was significantly elevated in $\alpha$-mangostin-treated cells. This strongly suggests that a-mangostin induces apoptosis via the mitochondria-mediated pathway. However, since no Bid cleavage was seen, the mitochondriamediated apoptosis induced by a-manogstin may not be through the caspase-8-Bid pathway. The results in in vivo experiments were similar in that we observed higher expression of the active forms of caspase- 3 and caspase- 9 in mice mammary carcinomas exposed to $\alpha$-mangostin via the mini-osmotic pumps as compared to control tumors, suggesting that $\alpha$-mangostin induces the same mechanism in vivo as well as in vitro.

Cell cycle analysis: As measured by flow cytometry, we found an increased number of BJMC3879Luc2 cells in the G1-phase and a decrease of cells in the S-phase after treatment with $12 \mu \mathrm{M} \alpha$-mangostin.

Akt phosphorylation: Akt phosphorylation contributes not only to cell proliferation but also to anti-apoptotic cell death, cell cycle entry, angiogenesis and metastasis- all important aspects of the oncogenic process [22]. We found that treatment with $\alpha$-mangostin significantly decreased phospho-Akt expression in both mammary carcinoma cells in vitro and in mammary carcinoma tissues in vivo. Given this correlation, the phosphatidylinositol 3-kinase (PI3K)/Akt/mammalian target of rapamycin (mTOR) pathway, which is activated in many solid cancer patients, may be a target in cancer therapeutics [23].

\section{Analysis of Apoptosis and Cell Cycle Arrest in Human Breast Carcinoma Cells Treated with Purified a-Mangostin}

We used MDA-MB231 human breast cancer cells for these analyses, comparing naïve cultures to those treated with $20 \mu \mathrm{M} \alpha$-mangostin. Exposure to $\alpha$-mangostin increased apoptosis as evaluated by ssDNA levels and increased levels of caspase-3, caspase-8 and caspase-9; along with significant cytochrome $c$ release, this would indicates a-mangostin-induced apoptosis to be mitochondria-mediated and in agreement with our previous studies [11,12].

a-mangostin also induced G1-phase arrest and decreased PCNA levels indicated S-phase suppression. Cell cycle arrest was associated with upregulation of $\mathrm{p} 21^{\mathrm{cip} 1}$, a cyclin-dependent kinase inhibitor, and check-point protein 2 (Chk2), a cell cycle checkpoint regulator.

\section{Discussion}

Both panaxanthone, a crude mixture consisting of $75-85 \%$ $\alpha$-mangostin and 5-15\% $\gamma$-mangostin, and purified $\alpha$-mangostin exerted anti-tumor effects in immunocompetent mice inoculated with 
a mammary cancer xenograft containing a $p 53$ mutation that induces a metastatic spectrum similar to that seen in human breast cancer $[11,12]$. Other animal cancer models also demonstrate the anti-tumor effects of mangosteen extracts. For example, $\alpha$-mangostin inhibited 7,12-dimethylbenz $[\alpha]$ anthracene (DMBA)-induced preneoplastic lesions in a mouse mammary organ culture assay [24], while dietary administration of crude a-mangostin significantly inhibited the development of preneoplastic aberrant crypt foci in rat colon carcinogenesis and is associated with decreased expression of PCNA and increased $\beta$-catenin accumulated in the crypts [8]. In addition, crude $\alpha$-mangostin in the diet significantly suppressed colon tumor growth in a nude mouse xenograft model using HCT 116 human colorectal carcinoma cells [9]. Furthermore, crude $\alpha$-mangostin demonstrated decreases in cell migration, cell invasion and clonogenicity, as well as induction of apoptosis via mitochondrial pathway in in vitro studies. In prostate cancer, treatment with $\alpha$-mangostin by oral gavage $(100 \mathrm{mg} / \mathrm{kg})$ significantly suppressed xenograft tumor growth induced with human prostate carcinoma 22Rv1 cells in nude mice; this growth suppression is associated with cell-cycle arrest at G1-phase and apoptosis, possibly due to inhibition of cyclins/cyclin-dependent kinase 4 (Cdk4), a critical component of the G1-phase. In two different skin cancer cell lines (human melanoma SK-MEL-28 cells and human squamous cell carcinoma A431 cells), a-mangostin inhibited motility, adhesion, migration and invasion in vitro study, showing anti-metastatic ability [25].

We similarly observed G1-phase arrest and S-phase suppression in the cell cycle and mitochondria-mediated apoptosis in mammary carcinoma cells treated with $\alpha$-mangostin $[12,13]$. Furthermore, it has shown that transcription levels of $\mathrm{p} 21^{\mathrm{Cip} 1}$ and Chk2 are up-regulated in a-mangostin-treated mammary carcinoma cells [13]. The likely anti-tumorigenic mechanisms induced by $\alpha$-mangostin are illustrated in Figure 3. p2 $1^{\mathrm{cip} 1}$ and Chk2 act as a break at G1-phase of cell cycle and activation of the Cdk inhibitor p $21^{\text {Cipl }}$ leads to the inhibition of the Cyclin E/A-Cdk2 complex, which causes cell-cycle arrest at the G1/S boundary. Chk2 kinase is further responsible for inhibitory phosphorylation of Cdc25A, a phosphatase required for activation of Cdks2/4/6, resulting in cell-cycle arrest.

a-mangostin also inhibits Akt phosphorylation in mammary carcinoma cells both in vitro and in vivo [12] and similarly decreases phosphorylation of Akt as well as MAPK in DLD1colorectal cancer cells [5]. Akt is considered to be the key downstream effector of PI3K oncogenic signaling. Given the crucial role of PI3K/Akt signaling in regulating processes such as cell growth, proliferation, migration, and survival and in angiogenesis and anti-apoptosis [22], it is not surprising that components of this pathway are frequently dysregulated in cancer, making the Akt kinase family members important therapeutic targets. This pathway is frequently dysregulated in human cancer and modulates many of the characteristic processes of tumorigenesis [26], including cell growth, proliferation, survival, migration, metabolism, and tumor angiogenesis, offering another pivotal target for cancer therapy [27]. In fact, our experiments demonstrated that treatment with $\alpha$-mangostin showed Akt dephosphorylation [12], inhibition of tumor angiogenesis and induction of apoptosis [11,12]. Since Akt exists up-stream of these processes, a-mangostin-induced dephosphorylation may be one possible mechanism for its anti-tumor action (Figure 3).

Both $\alpha$ - and $\gamma$-mangostin inhibit aromatase in a dose-dependent manner, so that this is another possible mechanism by which a-mangostin exerted the anti-tumorigenic effects seen in our

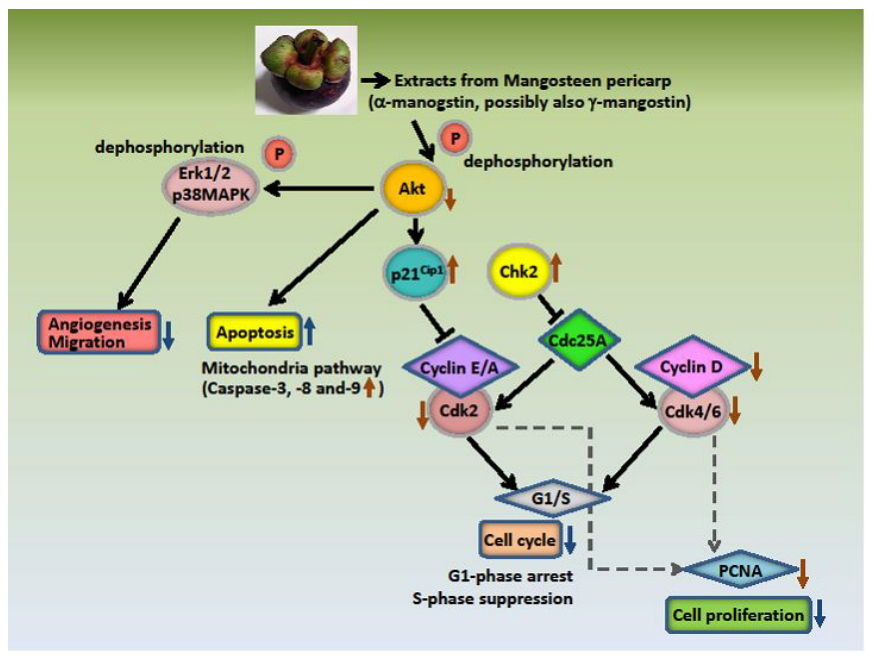

Figure 3: Possible mechanistic pathway of $\alpha$-mangostin's antitumorigenic effects. Akt phosphorylation contributes not only to cell proliferation but also to anti-apoptotic cell death, cell cycle entry, angiogenesis and metastasis-all important aspects of the oncogenic process. Since Akt exist up-stream of these processes, $\alpha$-mangostin-induced dephosphorylation may be one possible mechanism for its anti-tumor action.

experiments. Estrogen and the estrogen receptor a (ER $\alpha)$ are widely accepted as playing a crucial role in the development and progression of hormone-dependent breast cancer. Aromatase is an estrogen synthase responsible for catalyzing the biosynthesis of estrogens from androgens, making it another attractive therapeutic target in treating breast cancer. Currently, use of third-generation aromatase inhibitors are common as standard adjuvant therapy for postmenopausal breast cancer patients having hormone-receptor positive disease and are associated with improved disease-free survival compared with the previous standard tamoxifen therapy $[28,29]$.

\section{Conclusion}

Our studies provide correlating evidence for mangosteen extracts as potential chemopreventive or anti-cancer agents. Of particular significance is the in vivo reduction of lymph node metastasis by a-mangostin; since metastasis is the most important prognostic factor in breast cancer patients, this anti-metastatic action of certain fractions of mangosteen suggests specific clinical applications, at least in breast cancer carrying p53 mutation. Mangosteen extracts appear to, in fact, have chemopreventive qualities and might prove useful as adjunctive and/or complementary alternative treatments in human breast cancer.

\section{Acknowledgement}

These investigations involved Industry-Academic-Government collaboration as follows: PM Riken-yakka Ltd., Field \& Device Co., Osaka Health Science University, Osaka Medical College, and Gifu Pharmaceutical University. This work was also partially supported by a Grant-in-Aid for Science Research (C) (2) from the Ministry of Education, Culture, Sports, Science and Technology of Japan (Research Project No.24591924 to MA Shibata). We thank Ms. Naomi Nakano (Osaka Health Science University) for their excellent secretarial assistance.

\section{References}

1. Wexler B (2007) Mangosteen. Utah, USA, Woodland Publishing.

2. Matsumoto K, Akao Y, Ohguchi K, Ito T, Tanaka T, et al. (2005) Xanthones induce cell-cycle arrest and apoptosis in human colon cancer DLD-1 cells. Bioorg Med Chem 13: 6064-6069.

3. Matsumoto K, Akao Y, Yi H, Ohguchi K, Ito T, et al. (2004) Preferential target is 
Citation: Shibata MA, Matoba Y, Tosa H, linuma M (2013) Effects of Mangosteen Pericarp Extracts Against Mammary Cancer. Altern Integ Med 2: 139. doi:10.4172/2327-5162.1000139

mitochondria in alpha-mangostin-induced apoptosis in human leukemia HL60 cells. Bioorg Med Chem 12: 5799-5806.

4. Moongkarndi P, Kosem N, Kaslungka S, Luanratana O, Pongpan N, et al. (2004) Antiproliferation, antioxidation and induction of apoptosis by Garcinia mangostana (mangosteen) on SKBR3 human breast cancer cell line. $J$ Ethnopharmacol 90: 161-166.

5. Nakagawa Y, linuma M, Naoe T, Nozawa Y, Akao Y (2007) Characterized mechanism of alpha-mangostin-induced cell death: caspase-independent apoptosis with release of endonuclease- $G$ from mitochondria and increased miR-143 expression in human colorectal cancer DLD-1 cells. Bioorg Med Chem 15: 5620-5628.

6. Hung SH, Shen KH, Wu CH, Liu CL, Shih YW (2009) alpha-Mangostin suppresses PC-3 human prostate carcinoma cell metastasis by inhibiting matrix metalloproteinase-2/9 and urokinase-plasminogen expression through the JNK signaling pathway. J Agric Food Chem 57: 1291-1298.

7. Lee YB, Ko KC, Shi MD, Liao YC, Chiang TA, et al. (2010) alpha-Mangostin, a novel dietary xanthone, suppresses TPA-mediated MMP-2 and MMP9 expressions through the ERK signaling pathway in MCF-7 human breast adenocarcinoma cells. J Food Sci 75: H13-H23.

8. Nabandith V, Suzui M, Morioka T, Kaneshiro T, Kinjo T, et al. (2004) Inhibitory effects of crude alpha-mangostin, a xanthone derivative, on two different categories of colon preneoplastic lesions induced by 1, 2-dimethylhydrazine in the rat. Asian Pac J Cancer Prev 5: 433-438.

9. Aisha AF, Abu-Salah KM, Ismail Z, Majid AM (2012) In vitro and in vivo anti-colon cancer effects of Garcinia mangostana xanthones extract. BMC Complement Altern Med 12: 104

10. Johnson JJ, Petiwala SM, Syed DN, Rasmussen JT, Adhami VM, et al. (2012) alpha-Mangostin, a xanthone from mangosteen fruit, promotes cell cycle arrest in prostate cancer and decreases xenograft tumor growth. Carcinogenesis 33 : 413-419.

11. Doi H, Shibata MA, Shibata E, Morimoto J, Akao Y, et al. (2009) Panaxanthone isolated from pericarp of Garcinia mangostana L. suppresses tumor growth and metastasis of a mouse model of mammary cancer. Anticancer Res 29 : 2485-2495.

12. Shibata MA, linuma M, Morimoto J, Kurose H, Akamatsu K, et al. (2011) alpha-Mangostin extracted from the pericarp of the mangosteen (Garcinia mangostana Linn) reduces tumor growth and lymph node metastasis in an immunocompetent xenograft model of metastatic mammary cancer carrying a p53 mutation. BMC Med 9: 69.

13. Kurose H, Shibata MA, linuma M, Otsuki $Y$ (2012) Alterations in cell cycle and induction of apoptotic cell death in breast cancer cells treated with alphaMangostin extracted from mangosteen pericarp. J Biomed Biotechnol 2012: 672428.

14. Morimoto J, Imai S, Haga S, Iwai Y, Iwai M, et al. (1991) New murine mammary tumor cell lines. In Vitro Cell Dev Biol 27A: 349-351.

15. Shibata MA, Morimoto J, Otsuki Y (2002) Suppression of murine mammary carcinoma growth and metastasis by HSVtk/GCV gene therapy using in vivo electroporation. Cancer Gene Ther 9: 16-27.

16. Shibata MA, Ito Y, Morimoto J, Kusakabe K, Yoshinaka R, et al. (2006) In vivo electrogene transfer of interleukin-12 inhibits tumor growth and lymph node and lung metastases in mouse mammary carcinomas. J Gene Med 8: 335-352.

17. Shibata MA, Akao Y, Shibata E, Nozawa Y, Ito T, et al. (2007) Vaticanol C, a novel resveratrol tetramer, reduces lymph node and lung metastases of mouse mammary carcinoma carrying p53 mutation. Cancer Chemother Pharmacol 60: 681-691.

18. Shibata MA, Liu ML, Knudson MC, Shibata E, Yoshidome K, et al. (1999) Haploid loss of bax leads to accelerated mammary tumor development in C3(1)/SV40-TAg transgenic mice: reduction in protective apoptotic response at the preneoplastic stage. EMBO J 18: 2692-2701.
19. Shibata MA, Shibata E, Morimoto J, Eid NA, Tanaka Y, et al. (2009) An immunocompetent murine model of metastatic mammary cancer accessible to bioluminescence imaging. Anticancer Res 29: 4389-4395

20. Shibata MA, Morimoto J, Shibata E, Kurose H, Akamatsu K, et al. (2010) Raloxifene inhibits tumor growth and lymph node metastasis in a xenograft model of metastatic mammary cancer. BMC Cancer 10: 566

21. Shibata MA, Ambati J, Shibata E, Albuquerque RJ, Morimoto J, et al. (2010) The endogenous soluble VEGF receptor-2 isoform suppresses lymph node metastasis in a mouse immunocompetent mammary cancer model. BMC Med 8: 69

22. Agarwal A, Das K, Lerner N, Sathe S, Cicek M, et al. (2005) The AKT/I kappa B kinase pathway promotes angiogenic/metastatic gene expression in colorectal cancer by activating nuclear factor-kappa B and beta-catenin. Oncogene 24 : 1021-1031.

23. Loh AH, Brennan RC, Lang WH, Hickey RJ, Malkas LH, et al. (2013) Dissecting the PI3K Signaling Axis in Pediatric Solid Tumors: Novel Targets for Clinical Integration. Front Oncol 3: 93.

24. Jung HA, Su BN, Keller WJ, Mehta RG, Kinghorn AD (2006) Antioxidant xanthones from the pericarp of Garcinia mangostana (Mangosteen). J Agric Food Chem 54: 2077-2082.

25. Wang JJ, Sanderson BJ, Zhang W (2012) Significant anti-invasive activities of alpha-mangostin from the mangosteen pericarp on two human skin cancer cell lines. Anticancer Res 32: 3805-3816.

26. Sheppard K, Kinross KM, Solomon B, Pearson RB, Phillips WA (2012) Targeting PI3 kinase/AKT/mTOR signaling in cancer. Crit Rev Oncog 17: 6995.

27. De Luca A, Maiello MR, D'Alessio A, Pergameno M, Normanno N (2012) The RAS/RAF/MEK/ERK and the PI3K/AKT signalling pathways: role in cancer pathogenesis and implications for therapeutic approaches. Expert Opin Ther Targets 16 Suppl 2: S17-27.

28. Coombes RC, Hall E, Gibson LJ, Paridaens R, Jassem J, et al. (2004) A randomized trial of exemestane after two to three years of tamoxifen therapy in postmenopausal women with primary breast cancer. N Engl J Med 350: 1081-1092.

29. Howell A, Cuzick J, Baum M, Buzdar A, Dowsett M, et al. (2005) Results of the ATAC (Arimidex, Tamoxifen, Alone or in Combination) trial after completion of 5 years' adjuvant treatment for breast cancer. Lancet 365: 60-62. 